\title{
CiênCIA e Ideologia. O Caso da Física
}

\author{
Ana Henriques Pato ${ }^{1}$
}

(Centro de Filosofia das Ciências da Universidade de Lisboa)

\begin{abstract}
A ideologia tem um carácter de classe. Mas nem por isso exprime tão-só um estado de espírito. Na realidade, defende os interesses de classes e de camadas sociais determinadas. De onde se segue que para se fazer uma ideia exacta da sua significação histórica profunda, forçoso é aplicar sempre esta crítica de princípio a cada corrente ou tendência ideológica, pondo-se, entre outras, as seguintes perguntas de base: Que ideias sociais ela professa? A quem se dirige? Que interesses de classe serve? Ou ainda: Que tendências ideológicas contraditórias representam as obras em cada forma da consciência social e como, precisamente, elas representam estas tendências? Enfim, em quê e de que são representativas? Todas estas perguntas colocam-se-nos hoje; e estas não são as únicas. ${ }^{2}$
\end{abstract}

Estas palavras são de Vasco de Magalhães-Vilhena e constituem o parágrafo inaugural do seu escrito Da Ideia de Progresso na Antiguidade.

Pois é precisamente a esta "crítica de princípio" que o homenageado incansavelmente tantas vezes procede. O que revela, desde logo, no seu método, na sua forma de inquirição, aquela que é a sua orientação marxista.

\footnotetext{
1 anahpato@gmail.com

2 Vasco de Magalhães-Vilhena, "Da Ideia de Progresso na Antiguidade", in Antigos $e$ Modernos. Estudos Sociais de História das Ideias, Lisboa: Livros Horizonte, 1984, p. 99.
}

Philosophica, 49, Lisboa, 2017, pp. 81-89. 
A ciência esteve tantas vezes sob a sua mira. Ou não fosse a ciência, como o próprio afirma, "uma forma peculiar da consciência social"3. A publicação no ano passado pelo Grupo de Estudos Marxistas do livro Fragmentos sobre Ideologia com excertos inéditos de Magalhães-Vilhena - que culmina um esforço de, nomeadamente, Eduardo Chitas a que o João Fagundes deu continuidade - é um óptimo contributo para aclarar a posição do autor sobre esta relação entre ideologia e ciência.

Mas a ciência não é só "uma manifestação da vida espiritual da sociedade"4. Ela constitui também uma força produtiva. E este duplo significado da ciência, em toda a unidade destes dois aspectos - que será o mesmo que dizer, em toda a unidade da teoria e da prática - constitui uma linha básica orientadora das suas investigações nas quais revela a íntima relação entre ciência, técnica e estruturas sociais ${ }^{5}$.

É o próprio que nos diz, em entrevista, que sempre se interessara muito especialmente pelos problemas gnosiológicos levantados pela ciência $^{6}$ e pelas implicações filosóficas dos novos fundamentos da ciência. Não é, assim, por acaso que é chamado para colaborar num curso de Filosofia da Ciência com o tema "Introdução Física e Filosófica à Teoria dos Quanta" o qual, em pleno fascismo, não chegou a oferecer mais do que quatro lições ${ }^{7}$.

Lénine mostrara, na sua obra Materialismo e Empiriocriticismo, como, na ciência do seu tempo, sob diferentes roupagens e terminologias e subterfúgios, se opunham, o materialismo e o idealismo - como duas correntes filosóficas fundamentais que são.

Precisamente dentro do mesmo espírito, Magalhães-Vilhena afirmava que, na medida em que a démarche científica e filosófica se interceptam, se determinam mutuamente, "um cientista, tanto como um filósofo, não o é sem tomar uma posição de partido. E isto quer ele o queira com um propósito firme ou não, quer seja disso consciente ou, em boa consciência, o ignore inteiramente"s.

\footnotetext{
${ }^{3}$ Vasco de Magalhães-Vilhena, "Ideia e Matéria. A Teoria, Força Material”, in ibid., p. 283.

${ }^{4}$ Ibid.

5 Ver, por exemplo, Vasco de Magalhães-Vilhena, "Surto Técnico e Científico e "Blocagem" Social na Cidade Antiga", in ibid., p. 34.

${ }^{6}$ Eduardo Chitas, Hernâni A. Resende (coord.), Filosofia. História. Conhecimento. Homenagem a Vasco de Magalhães-Vilhena, Lisboa: Caminho, 1990, p. 333.

7 Cf. ibid., p. 299. O curso fora ministrado na Universidade de Coimbra, tendo como promotores o prof. Mário Silva e o prof. Guido Beck, que fora colaborador de Einstein. Como se pode ler neste texto de Manuel Deniz-Jacinto, o prof. Guido Beck acabaria por ser posto na fronteira pela PIDE e, quatro anos depois, em 1946, o prof. Mário Silva seria aposentado compulsivamente pelo governo de Salazar.

${ }^{8}$ Vasco de Magalhães-Vilhena, Fragmentos sobre Ideologia, Lisboa: Grupo de Estudos Marxistas, 2015, p. 41.
} 
As incidências da ideologia, como ele nos chama a atenção, "são forçosamente as mais variadas e as mais variáveis, segundo a natureza específica de cada ciência e do seu contexto histórico real, bem como do contexto do seu desenvolvimento". E exemplifica: "A intromissão da ideologia burguesa na formação e no desenvolvimento da economia política clássica, por exemplo, não tem evidentemente nada em comum com a que se pode detectar na formação da física clássica pré-quântica"".

No caso da física, Lénine chegou mesmo a utilizar a expressão "idealismo físico" para designar essa tendência de uma certa escola de físicos dos fins do século XIX e início do século XX.

Nos dias de hoje, a mecânica quântica é um campo da ciência que suscita inúmeros problemas filosóficos que estão longe de estar resolvidos. Hoje o debate continua, envolvendo cientistas e filósofos. É sobre este campo da física que me debruçarei.

Creio que uma tarefa que se impõe, no seio deste debate, é procurar compreender em que medida e de que forma as diferentes interpretações da mecânica quântica são, na raíz das suas diferenças e oposições, esse confronto mais fundamental entre o materialismo e o idealismo.

Há hoje uma interpretação dominante da mecânica quântica. É a interpretação vigente, muito embora o possa ser de forma apenas de forma tácita ou operativa. É a chamada interpretação ortodoxa ou de Copenhaga. Para ela, fortemente contribuiu o pensamento do grande físico Niels Bohr, um dos fundadores deste ramo da ciência.

Ora, defendo ${ }^{10}$ que esta interpretação está fortemente marcada por tendências agnósticas e idealistas.

Não são os resultados científicos que estão em causa. Mas, sim, a interpretação que deles é feita. Aliás, Magalhães-Vilhena considera mesmo errado falar-se do carácter de classe das teorias científicas ${ }^{11}$; considera, com Marx, Engels e Lénine, que não se pode falar de "ciência proletária" e "ciência burguesa""

Porém, como acrescenta, não "se pode considerar fortuito que a física aristotélica (como, aliás, a de Platão) sejam dominadas pelo princípio teleológico e que uma e outra se oponham, muito naturalmente, neste ponto como em muitos outros, ao pensamento mecanicista dos materialistas" 13 .

\footnotetext{
${ }^{9}$ Ibid., p. 40.

${ }^{10}$ Ana Pato, Materialismo e Idealismo na Física do final do século XIX e início do século XX a partir de Materialismo e Empiriocriticismo de Lénine. O caso exemplar da interpretação bohriana da mecânica quântica, Paris: Nota de Rodapé Edições, 2015.

${ }^{11}$ Cf. Vasco de Magalhães-Vilhena, Fragmentos sobre Ideologia, Lisboa: Grupo de Estudos Marxistas, 2015, p. 41.

${ }^{12}$ Cf. Ibid. p. 79.

${ }^{13}$ Ibid., p. 41.
} 
E assim é porque "O pensamento teórico, como pensamento, não é de todo independente nem por completo autónomo das condições históricas e materiais, antes histórica, social e materialmente condicionado"14. E se há choques entre tendências ideológicas, se, pondo de forma mais geral, há movimento ideológico, é porque ele é o reflexo, mais ou menos directo, mais ou menos mediado, do movimento material.

E esta consideração baliza, como não podia deixar de ser, o progresso da própria ciência: ele faz-se através da colocação e resolução de contradições.

Assim, como causa motriz para o seu desenvolvimento, encontramos a resolução quer das contradições entre a ciência e o desenvolvimento das forças produtivas, quer das contradições internas ao próprio corpo de conhecimentos (seja no interior da teoria, seja entre a teoria e a experiência) ${ }^{15}$.

A história do conhecimento científico fornece-nos inúmeros exemplos de contradições desta natureza. Ora, foi deste tipo de contradições que a teoria quântica emergiu e se desenvolveu.

É pois interessante descobrir, através de David Cassidy ${ }^{16}$ (revelando um aspecto que suponho ser ainda pouco estudado), as ligações com as necessidades económicas da época: sucede que os cientistas do gabinete de padrões, em Berlim, estavam interessados em estabelecer os padrões para a emergente indústria eléctrica de iluminação. Mediam a distribuição total da energia electromagnética emitida por uma caixa preta, o que se pode aplicar a uma lâmpada incandescente de que o chamado "corpo negro" é uma idealização. Daqui nasceu a hipótese dos quanta de luz, introduzida por Planck.

Os físicos ficaram perante um "dilema".

Descobrira-se que a matéria, quer se tratasse de partículas, quer se tratasse de radiação, tinha um comportamento ondulatório e corpuscular. Mas nunca simultaneamente. Os arranjos experimentais nunca revelavam essas características ao mesmo tempo. E aqui reside a grande dificuldade.

${ }^{14}$ Vasco de Magalhães-Vilhena, "Ideia e Matéria. A Teoria, Força Material", in Antigos e Modernos. Estudos Sociais de História das Ideias, Lisboa: Livros Horizonte, 1984, p. 266.

${ }^{15}$ Cf. Herbert Hörz, Hans-Dieter Pöltz, Heinrich Parthey, Ulrich Röseberg, Karl-Friederich Wessel, Philosophical Problems in Physical Science, Minneapolis: Marxist Educational Press, 1980, p. 71.

${ }^{16}$ David Cassidy, Einstein on the Photoelectric effect (adaptado do livro David Cassidy, Einstein and Our World, Humanities Press, 1995, reissued Amherst, NY: Humanity Books, 1998), American Institute of Physics Center for History of Physics, 13-07-2012, 11:55. Disponível em http://www.aip.org/history/einstein/essay-photoelectric.htm 
O tal "dilema" a que Bohr se refere. Estamos perante o chamado "dualismo onda-corpúsculo". Que é, nas palavras de Rui Moreira, "o maior problema herdado da física do século XX" ${ }^{17}$ e está, como reconhece José Croca, na base do surgimento do princípio da complementaridade de Bohr ${ }^{18}$.

Ora, penso que é na forma de lidar com esta contradição - objectiva e subjectiva - que, em grande medida, reside o problema.

Segundo o princípio da complementaridade, as características ondulatórias e corpusculares da matéria seriam complementares, no sentido em não seria possível reuni-las numa única imagem. Ou, dito de outra maneira, seriam mutuamente exclusivas. Para Bohr, os objectos quânticos só podiam ser ou onda ou corpúsculo. Bohr introduziu uma linha rígida (daquelas que Engels dizia não existirem na Natureza).

Da mesma forma, também não seria possível obter simultaneamente uma descrição causal e uma descrição espácio-temporal dos fenómenos quânticos. Estamos - no quadro da interpretação ortodoxa - perante a negação da universalidade da causalidade, preservando-se um certo grau de indeterminismo para os acontecimentos quânticos.

E a este princípio Bohr procura atribuir-lhe toda a generalidade, estendendo-o a outras áreas, procurando elevá-lo, na verdade, a um princípio epistemológico.

O princípio da complementaridade obrigaria a assumir como elementares, como não sujeitos a ulteriores análises, factos como o quantum ou a existência da vida. O que Bohr faz aqui é traçar limites para o conhecimento.

No quadro da relação entre ideologia, filosofia e ciência (tão abordada por Magalhães-Vilhena) é interessante notar a relação que Rui Moreira estabelece entre o pensamento de Bohr e o do seu professor de filosofia, Harald Høffding, segundo o qual existiria uma relação de complementaridade entre as funções psicológicas de ver e compreender, as quais seriam duas "necessidades inconciliáveis" do espírito humano. Trata-se do mesmo princípio já introduzido por este na filosofia e psicologia e que Bohr transpunha, agora, para a física.

De facto, uma das principais consequências - entre vários outros aspectos - da interpretação ortodoxa da mecânica quântica é o estabelecimento de limites últimos para o conhecimento.

17 Rui Nobre Moreira, "Instrumentalismo Versus Realismo, a Crise na Física do Século XX”, in Olga Pombo, Ángel Nepomuceno (eds.), Lógica e Filosofia da Ciência, Lisboa: Centro de Filosofia das Ciências da Universidade de Lisboa, 2009, p.137

18 Cf. José Croca, Towards a Nonlinear Quantum Physics, New Jersey/London/Singapore/ HongKong: World Scientific, 2003, p. 18. 
Esses limites encontram expressão nas relações de incerteza de Heisenberg, tomadas de forma absolutizada.

Isto relaciona-se com o facto de Bohr reduzir o objecto quântico (ou pelo menos o conhecimento que temos acerca dele) à sua manifestação fenoménica. Para Bohr, não é possível conhecer mais acerca das partículas quânticas para além da impressão que elas deixam numa placa fotográfica. É a imediatez dos fenómenos que não pode ser transposta.

Creio que, na base do princípio da complementaridade está uma não devida consideração da dialéctica da contradição real entre onda e corpúsculo. Dizer que a dialéctica não reconhece a existência daquelas linhas rígidas absolutas na Natureza é também dizer que as contradições reais objectivas não são pares de opostos colocados lado a lado, sem relação, sem interpenetração, sem condicionamento mútuo.

Bohr - isto é muito importante - reconhece e identifica a contradição entre onda e corpúsculo como tal. No entanto, não a resolve. Fixa-a. Bohr absolutiza na teoria a contradição existente entre onda e corpúsculo, lidando com ela de forma metafísica, impedindo, assim, a sua negação dialéctica, a sua superação.

A questão está, creio, em compreender o objecto quântico não como $o u$ onda ou corpúsculo, mas sim como onda e corpúsculo.

E há linhas de investigação que o procuram fazer. E é neste sentido que refiro haver oposições entre diferentes interpretações da mecânica quântica. E logo desde o início desta disciplina científica. As conhecidas e muito vivas e interessantes discussões entre Bohr e Einstein são disso expressão.

Em oposição à interpretação ortodoxa, no seguimento da linha de Louis de Broglie, desenvolvem-se outros programas de investigação. E estou a pensar nomeadamente na Escola de Lisboa. Em oposição no sentido em que assenta no expresso reconhecimento da existência de uma realidade objectiva (independente do observador) e na possibilidade de as teorias cientificas a reflectirem, combatendo directamente o estabelecimento de limites últimos para o conhecimento, combatendo o entendimento da ciência num sentido instrumentalista e defendendo uma teoria que seja causal.

Este ponto de partida, conduziu a uma proposta que parte da hipótese de que o ente quântico é constituído por uma parte ondulatória extensa e por uma parte corpuscular (uma singularidade designada ácron, designação, aliás, que tem o cunho de Eduardo Chitas). Põe a hipótese de o ente quântico exibir uma estrutura complexa.

Esta proposta não obriga, assim, a impor pela teoria a "desunião" de uma realidade que é una. Ela tem em conta, simultaneamente, a unidade da realidade e a complexidade da matéria. A matéria é inesgotável. 
Defender um ponto de vista materialista tem consequências: desde logo, a defesa firme da possibilidade do conhecimento científico, a defesa da objectividade da ciência; tem como consequência a separação da ciência das formas místicas e religiosas da consciência social.

Como o exemplo da mecânica quântica demonstra, a ciência actual não está liberta de interpretações idealistas e de utilizações místicas. Ciência e filosofia estão ligadas de forma indissolúvel. Por outras palavras, está fora de questão a ideia de que os cientistas não estão imersos num dado sistema de representações.

A propósito das formas que a luta de ideias assume (quer na sua expressão científica, quer filosófica, quer política) não deixa de ser interessante referir uma história que Magalhães-Vilhena nos conta. Dizia-nos ele que o célebre físico Werner Heisenberg, com o objectivo evidente de reforçar a sua concepção ideológica relativa ao que chama de "a decomposição do determinismo" 19 , reproduz no fim da parte antológica da sua obra um texto do grande físico Louis de Broglie que vai no mesmo sentido da concepção de Heisenberg.

Acontece que, como qualquer pessoa minimamente ao corrente das ideias da física contemporânea sabe, Louis De Broglie abandonou em 1952, com grande estrondo, as suas posições favoráveis, desde 1928 até aí, à interpretação indeterminista da física quântica para retomar o seu bosquejo de outrora e aderir, em parte sob a influência dos físicos materialistas David Bohm e Jean-Pierre Vigier, às posições do determinismo ${ }^{20}$.

Vilhena questiona as razões da omissão por Heisenberg daquilo a que o próprio Broglie designou "volte-face" e pergunta se será excessivo chamar a isto uma "falsificação deliberada por razões ideológicas", mas não sem lembrar que Heisenberg era, nas suas palavras, o Führer incontestado do III Reich hiteleriano.

Para concluir, como dizia Engels, a questão está em saber se os cientistas "querem ser dominados por uma má filosofia da moda ou por uma forma de pensamento teórico que assenta no conhecimento da história do pensamento e das suas realizações" ${ }^{21}$.

Vemos, a respeito das duas interpretações da mecânica quântica, que não é indiferente a adopção de uma ou outra linha filosófica.

${ }^{19}$ Magalhães-Vilhena remete-nos para pp. 55-58 da tradução francesa de 1962 de $L a$ Nature dans la Physique contemporaine, de Werner Heisenberg (Paris: Gallimard?)

${ }^{20}$ Vasco de Magalhães-Vilhena, Fragmentos sobre Ideologia, Lisboa: Grupo de Estudos Marxistas, 2015, pp. 80-81.

${ }^{21}$ Friederich Engels, Dialectics of Nature, in Karl Marx-Frederick Engels Collected Works, New York: International Publishers, v.25, 1987, p. 491. 
Filosofia e ciência interpenetram-se. Mas nem a filosofia substitui a ciência, nem a ciência substitui a filosofia. As "oposições na ciência resolvem-se, porém, através da própria ciência", diz Marx em Para a Questão Judaica. E serão os desenvolvimentos da ciência, será a prática a via para a refutação da existência de limites definitivos no conhecimento, tanto no domínio quântico, quanto no conhecimento científico em geral.

Creio que a filosofia materialista e dialéctica constitui um importante instrumento de análise (e também de transformação, como bem sabemos) e de defesa da racionalidade científica, pleno de actualidade e que o pensamento acerca da ciência actual reclama. 


\title{
RESUMO
}

As reflexões de Magalhães-Vilhena acerca da relação entre ciência e ideologia contribuem para lançar luz sobre as implicações filosóficas dos fundamentos da ciência, algo que esteve sob o olhar interessado do filósofo português. É tendo em mente o duplo significado da ciência enquanto força produtiva e "manifestação da vida espiritual da sociedade" que Magalhães-Vilhena orienta as suas investigações nas quais revela a íntima relação entre ciência, técnica e estruturas sociais. Para o autor, é necessário proceder à tal "crítica de princípio" que revele os posicionamentos de cada tendência ideológica. Nos dias de hoje, a mecânica quântica continua a suscitar inúmeros problemas filosóficos. Prestando homenagem ao trabalho de Vilhena, procuro mostrar a necessidade de se pensar de que forma as diferentes interpretações da mecânica quântica encerram, na raíz das suas oposições, esse confronto mais fundamental entre materialismo e idealismo. Pretendo, assim, mostrar, a pertinência e actualidade da tal "crítica de princípio".

Palavras-chave: Ciência - Ideologia - Materialismo - Idealismo - Mecânica quântica.

\begin{abstract}
The thoughts of Magalhães-Vilhena concerning the relation between science and ideology are a contribution to enlighten the philosophical implications of the groundings of science, something that was under the interested look of the portuguese philosopher. It is having in mind the double meaning of science as productive force and as "manifestation of society's spiritual life" that Magalhães-Vilhena guides his investigations in which he reveals the intimate relation between science, tecnique and social structures. For the author, it is necessary to perform that "criticism of principle" that reveals the positioning of each ideological tendency. Nowadays, quantum mechanics still rises a number of philosophical problems. Paying tribute to Vilhena's work, I try to show the necessity of thinking in which way the different interpretations of quantum mechanics bear, in the roots of their oppositions, that most fundamental confrontation between materialism and idealism. I therefore pretend to show the pertinence and topicality of such "criticism of principle".
\end{abstract}

Key-words: Science - Ideology - Materialism - Idealism - Quantum mechanics. 